\title{
The effect of birth season on diurnal variation of blood pressure in hypertensive patients
}

\author{
Belma Kalaycı', Fürüzan Köktürk², Süleyman Kalaycı ${ }^{3}$, Mustafa Umut Somuncu ${ }^{1}$ \\ ${ }^{1}$ Bülent Ecevit University Hospital Cardiology Department \\ ${ }^{2}$ Bülent Ecevit University, Biostatistics Department \\ ${ }^{3}$ Zonguldak Atatürk State Hospital
}

\begin{abstract}
Background. Birth season has been found to be related to cardiovascular disorders, but the underlying mechanisms are unclear. The aim of this study was to evaluate the relationship between birth season and diurnal variation in blood pressure (BP) parameters in hypertensive patients.

Material and methods. We enrolled 194 patients. The date of birth was recorded with the season of birth determined as winter (December-February), spring (March-May), summer (June-August) or autumn (September-November). All patients underwent 24-hour ambulatory blood pressure monitoring (ABPM) for evaluation of dipper or non-dipper status. We searched for the relationship between birth season and non-dipper status and other ABPM parameters.

Results. 93 patients were classified into the dipper hypertensive group and 101 patients were in the non-dipper hypertensive group. We did not find any association between non-dipper status and birth season in hypertensive patients $(\mathrm{p}=0.517)$. However, we found a significant relationship between diurnal variation in $\mathrm{BP}$ and birth season. This difference was observed between winter and spring season. We found a significant relationship between birth season and 24-hour diastolic BP, awake diastolic BP, sleep diastolic BP and sleep mean BP ( $p=0.035, p=0.037$, $\mathrm{p}=0.036, \mathrm{p}=0.032$, respectively). These ABPM parameters were lower in patients born in winter than in those born in spring.

Conclusion. Birth season was found to be related to diurnal variation in blood pressure in hypertensive patients. Hypertensive individuals born in winter had lower blood pressure than those born in spring.

Key words: birth season; blood pressure; diurnal variation; hypertension; winter

Arterial Hypertens. 2018, vol. 22, no. 3, pages: 120-126

DOI: $10.5603 /$ AH.a2018.0012
\end{abstract}

\section{Introduction}

Clinical evidence suggests that many cardiovascular disorders are related to birth season. In a large analysis, nine cardiovascular conditions were found to be related to birth season including: atrial fibrillation, essential hypertension, heart failure, angina, cardiac complications of care, cardiomyopathy, pre-infarction syndrome, mitral valve disorders and chronic myocardial ischemia [1]. Hypertension is one of the major risk factors for cardiovascular morbidity and mortality. Although there are many physiopathological explanations for hypertension, the main reason is essential, complex and multifactorial. There were several previous studies about birth season and hypertension or blood pressure (BP), with varying results. In one study, the individuals born in autumn had low-

\footnotetext{
Address for correspondence: Dr Belma Kalayci, MD, Assistant Professor Doctor Bulent Ecevit University, Department of Cardiology, 61600, Zonguldak, Turkey tel.: +905059136012, fax: + 903722572140 e-mail: drbelma@hotmail.com
}

V M Copyright $@ 2018$ Via Medica, ISSN 2449-6170 
er risk of hypertension than those born in winter [1]. Another study revealed that adult men born in spring had lower BP than those born in other seasons [2]. Therefore, we can say that the relationship between birth season and hypertension has not yet been fully elucidated. Diurnal variation in BP is detected by 24-hours (h) ambulatory blood pressure monitoring (ABPM). According to circadian rhythm, systolic and diastolic BP are expected to drop over $10 \%$ during the night compared to daytime in normal and hypertensive individuals (dipper). Non-dipper status is defined as the lack of nocturnal systolic and diastolic BP decline $\geq 10 \%$ compared to daytime values [3]. Diurnal blood pressure variation provides valuable information about cardiovascular prognosis in patients with hypertension. To our knowledge, the association between birth season and diurnal variation in $\mathrm{BP}$ in hypertensive patients has not been previously investigated. We aimed to investigate the relationship between birth season and diurnal variation in BP in hypertensive patients.

\section{Material and methods}

\section{Study design and study population}

Patients were selected from individuals referred to cardiology outpatient clinic for evaluation of hypertension from January 2015 to December 2016. The sample was selected by means of random multistage sampling. The study included 194 patients with newly diagnosed hypertension or essential hypertension. All patients underwent 24-h ABPM for evaluation of non-dipper status and diurnal blood pressure parameters. This study was consistent with the Declaration of Helsinki and was approved by the local Ethics and Research Committee of the University Hospital. The present study was a retrospective cross-sectional single-center study.

\section{Study parameters}

Patient records and data were accessed from the central database. Demographical information was recorded. The exact date of birth was available from identity data for all individuals. Season of birth was defined as winter (December-February), spring (March-May), summer (June-August) or autumn (September-November). All patients were evaluated for the presence of cardiovascular major risk factors, such as hypertension, diabetes mellitus and hyperlipidemia. Hypertension was defined as average systolic $\mathrm{BP} \geq 135 \mathrm{mmHg}$ and/or average diastolic $\mathrm{BP} \geq$ $85 \mathrm{mmHg}$ for daytime values with 24-h ABPM, previously diagnosed hypertension or use of any anti- hypertensive medications. The type of antihypertensive drugs used was recorded. Diabetes mellitus was defined as fasting plasma glucose levels higher than $126 \mathrm{mg} / \mathrm{dL}$ in multiple measurements, previously diagnosed diabetes mellitus or use of antidiabetic medications. Hyperlipidemia was defined as serum total cholesterol $\geq 240 \mathrm{mg} / \mathrm{dL}$, low-density lipoprotein cholesterol $\geq 130 \mathrm{mg} / \mathrm{dL}$, serum triglyceride $\geq 200 \mathrm{mg} / \mathrm{dL}$, use of lipid-lowering medication or previously diagnosed hyperlipidemia.

\section{$\mathrm{ABPM}$ recording}

ABPM was recorded during a routine day by a Del Mar Reynolds device (Tracker NIBP2, Hertford, UK). The cuff was placed around the non-dominant arm and was applied for $24 \mathrm{~h}$. BP was measured every $15 \mathrm{~min}$. during the daytime ( $7 \mathrm{am}$ to $10 \mathrm{pm}$ ) and every $30 \mathrm{~min}$. during nighttime (10 pm to $7 \mathrm{am}$ ). Patients were instructed to proceed their routine activities during the monitoring process and stay calm during the cuff inflation. The method was considered reliable if $>70 \%$ of the measurements were valid. The average values of systolic BP, diastolic BP and mean BP were calculated for daytime, nighttime and $24 \mathrm{~h}$ for each patient. We d efined dipping status as the percentage decline in nocturnal systolic BP and diastolic BP from day to night using the following formula: [(daytime BP mean) — (nighttime mean)]/ /(daytime BP mean) $\times 100$ [4]. Dipper BP status was defined as more than 10\% decrease in systolic and diastolic BP measurements. Patients with less than $10 \%$ decrease in either systolic BP or diastolic $\mathrm{BP}$ were defined as non-dipper BP status. According to dipping status, individuals were divided into two groups: dipper and non-dipper.

\section{Statistical analysis}

Statistical analyses were performed with SPSS 19.0 software. Distribution of data was determined by the Shapiro-Wilk test. Continuous variables were expressed as mean \pm SD (standard deviation) or median (minimum-maximum) and categorical variables as frequency and percent. Categorical variables were compared using the Pearson Chi-square test. Continuous variables were compared with independent sample t-test or the Mann-Whitney $U$ test for two groups. The one-way analysis of variance (ANOVA) or the Kruskal-Wallis test were used to determine the differences between more than two groups. The Tukey test was used as a post hoc test, if the Anova test was statistically significant. The Dunn's test was used for post hoc test after the Kruskal-Wallis test; $p$ value of less than 0.05 was considered statistically significant for all tests. 
Table I. Demographic and clinical characteristics

\begin{tabular}{|c|c|c|c|}
\hline Variables & Dipper hypertensive group ( $\mathbf{n}=93$ ) & Non-dipper hypertensive group $(\mathrm{n}=101)$ & p \\
\hline Age, years, mean \pm SD & $52.8 \pm 12.7$ & $55.5 \pm 14.7$ & 0.180 \\
\hline Sex, male, $\mathrm{n}(\%)$ & $42(45.2)$ & $39(38.6)$ & 0.356 \\
\hline Diabetes, n (\%) & $20(23.5)$ & $25(25.5)$ & 0.890 \\
\hline Hyperlipidemia, n (\%) & $27(32.1)$ & $39(42.4)$ & 0.161 \\
\hline Antihypertensive drug usage, $\mathrm{n}(\%)$ & $58(62.4)$ & $74(74)$ & 0.082 \\
\hline - ACEi/ARB, n (\%) & $41(44.1)$ & $65(64.4)$ & 0.005 \\
\hline — Beta Blocker, n (\%) & $21(22.6)$ & $30(29.7)$ & 0.336 \\
\hline - CCB, n (\%) & $26(28)$ & $26(25.7)$ & 0.728 \\
\hline — Diuretics, n (\%) & $11(11.8)$ & $42(41.6)$ & $<0.001$ \\
\hline — Alpha blocker, n (\%) & $3(3.2)$ & $9(8.9)$ & 0.179 \\
\hline Combined, n (\%) & $33(35.5)$ & $51(50.5)$ & 0.035 \\
\hline Glucose, mg/dL, median [min-max] & $103[78-403]$ & $101[76-364]$ & 0.443 \\
\hline Creatinine, mg/dL, median [min-max] & $0.9[0.5-1.7]$ & $1.0[0.4-9]$ & 0.187 \\
\hline Hemoglobin, $\mathrm{g} / \mathrm{dL}$, mean $\pm \mathrm{SD}$ & $13.3 \pm 1.7$ & $12.9 \pm 1.8$ & 0.098 \\
\hline Total Cholesterol, $\mathrm{mg} / \mathrm{dL}$, mean \pm SD & $195 \pm 40$ & $198 \pm 40$ & 0.595 \\
\hline $\mathrm{HDL}, \mathrm{mg} / \mathrm{dL}$, median [min-max] & 50 [27-83] & $49[12-100]$ & 0.507 \\
\hline LDL, mg/dL, median [min-max] & 114 [48-244] & $113[38-246]$ & 0.394 \\
\hline Triglycerides, mg/dL, median [min-max] & 153 [44-541] & $135[42-514]$ & 0.274 \\
\hline
\end{tabular}

ACEi — angiotensin converting enzyme inhibitor; ARB — angiotensin receptor blockers; CCB — calcium channel blocker; HDL — high density lipoprotein; LDL — low density lipoprotein

\section{Results}

Ninety-three patients were in the dipper hypertensive group and 101 patients were in the non-dipper hypertensive group. The demographic and clinical characteristics of dipper and non-dipper hypertensive groups are presented in Table I. We did not find significant differences between the two groups except in the type of antihypertensive drug used. Although antihypertensive drug usage was similar in both groups, angiotensin-converting enzyme inhibitor/angiotensin receptor blockers, diuretics and combined antihypertensive drug usage was significantly higher in the non-dipper hypertensive group by $\mathrm{p}=0.005, \mathrm{p}<0.001$ and $\mathrm{p}=0.035$, respectively.

Comparison of 24-h ABPM parameters between dipper and non-dipper hypertensive groups is shown in Table II. Awake BP parameters were lower and sleep blood pressure parameters were higher in the non-dipper hypertensive group. ABPM parameters were compared according to the season of birth as shown in Table III, Figure 1 and Figure 2. We found a significant relationship between birth season and 24-hour diastolic BP, awake diastolic BP, sleep diastolic BP and sleep mean BP. Sleep BP was found to be different in those two groups $(\mathrm{p}=0.035$, $\mathrm{p}=0.037, \mathrm{p}=0.036, \mathrm{p}=0.032$, respectively). The binary comparative analysis was used to determine whether this difference was caused by the winter season. 24hour diastolic BP, awake diastolic BP, sleep diastolic $\mathrm{BP}$ and sleep mean BP were lower in patients born in the winter season than in those born in spring. The night decrease ratio was similar in the season groups $(\mathrm{p}=0.874)$. We also did not find any association between non-dipper status and the season of birth as shown in Table IV $(\mathrm{p}=0.517)$.

\section{Discussion}

Our results show that hypertensive individuals born in winter had lower BP than those born in spring, although there was no association between non-dipper status and birth season. This finding can be explained with several hypotheses such as sunlight, plasma $25(\mathrm{OH}) \mathrm{D}$ level in prenatal and early postnatal period, maternal $25(\mathrm{OH}) \mathrm{D}$ status and some hormones related to ultraviolet light.

There are several studies about the relationship between blood pressure and birth season. They provide different findings. An animal trial investigated cardiac morphologic measurements by echocardiography among pigs born in all seasons. Cardiac wall 
Table II. Comparison of 24-h ambulatory blood pressure monitoring parameters between two groups

\begin{tabular}{|c|c|c|c|}
\hline Variables & Dipper hypertensive group $(\mathbf{n}=93$ ) & Non-dipper hypertensive group ( $\mathrm{n}=101$ ) & $\mathbf{p}$ \\
\hline $\begin{array}{l}\text { 24-h SBP [mmHg] } \\
\text { mean } \pm \text { SD }\end{array}$ & $134 \pm 13$ & $133 \pm 17$ & 0.762 \\
\hline $\begin{array}{l}\text { 24-h DBP [mmHg] } \\
\text { median [min-max] }\end{array}$ & $81[60-108]$ & $77[56-113]$ & 0.070 \\
\hline $\begin{array}{l}\text { 24-h MBP }[\mathrm{mmHg}] \\
\text { mean } \pm \text { SD }\end{array}$ & $92 \pm 9$ & $91 \pm 13$ & 0.426 \\
\hline $\begin{array}{l}\text { Awake SBP }[\mathrm{mmHg}] \\
\text { mean } \pm \text { SD }\end{array}$ & $139 \pm 13$ & $135 \pm 18$ & 0.047 \\
\hline $\begin{array}{l}\text { Awake DBP [mmHg] } \\
\text { median [min-max] }\end{array}$ & $85[61-114]$ & $78[57-116]$ & 0.001 \\
\hline $\begin{array}{l}\text { Awake MBP }[\mathrm{mmHg}] \\
\text { mean } \pm \text { SD }\end{array}$ & $96 \pm 10$ & $92 \pm 13$ & 0.008 \\
\hline $\begin{array}{l}\text { Sleep SBP [mmHg] } \\
\text { median [min-max] }\end{array}$ & 119 [89-152] & $128[94-178]$ & $<0.001$ \\
\hline $\begin{array}{l}\text { Sleep DBP [mmHg] } \\
\text { median [min-max] }\end{array}$ & 69 [51-97] & 74 [54-117] & $<0.001$ \\
\hline $\begin{array}{l}\text { Sleep MBP [mmHg] } \\
\text { median [min-max] }\end{array}$ & $80[60-107]$ & $86[64-130]$ & $<0.001$ \\
\hline $\begin{array}{l}\text { Night decrease ratio \% } \\
\text { median [min-max] }\end{array}$ & 18 [10-35] & 4.6 [from -13 to -9$]$ & $<0.001$ \\
\hline
\end{tabular}

DBP — diastolic blood pressure; MBP — mean blood pressure; SBP — systolic blood pressure

Table III. Comparison of 24-h ambulatory blood pressure monitoring parameters according to birth season

\begin{tabular}{|c|c|c|c|c|c|}
\hline Variables & $\begin{array}{l}\text { Winter } \\
(\mathrm{n}=53)\end{array}$ & $\begin{array}{c}\text { Spring } \\
(\mathrm{n}=62)\end{array}$ & $\begin{array}{l}\text { Summer } \\
(\mathrm{n}=39)\end{array}$ & $\begin{array}{l}\text { Autumn } \\
(\mathrm{n}=40)\end{array}$ & p \\
\hline $\begin{array}{l}\text { 24-h SBP [mmHg] } \\
\text { median [min-max] }\end{array}$ & 127 [99-173] & 135 [96-186] & 134 [95-177] & 134 [105-166] & 0.167 \\
\hline $\begin{array}{l}\text { 24-h DBP [mmHg] }{ }^{1} \\
\text { median [min-max] }\end{array}$ & 75 [56-102] & 83 [56-113] & 78 [57-105] & 80 [60-108] & 0.035 \\
\hline $\begin{array}{l}\text { 24-h MBP [mmHg] } \\
\text { median [min-max] }\end{array}$ & 88 [68-115] & 94 [65-127] & 90 [65-119] & 91 [72-122] & 0.071 \\
\hline $\begin{array}{l}\text { Awake SBP [mmHg] } \\
\text { median [min-max] }\end{array}$ & 132 [99-180] & 137 [97-189] & 137 [96-178] & 137 [110-168] & 0.174 \\
\hline $\begin{array}{l}\text { Awake DBP }[\mathrm{mmHg}]^{2} \\
\text { mean } \pm \mathrm{SD}\end{array}$ & $78 \pm 10$ & $84 \pm 11$ & $82 \pm 11$ & $84 \pm 12$ & 0.037 \\
\hline $\begin{array}{l}\text { Awake MBP }[\mathrm{mmHg}] \\
\text { mean } \pm \text { SD }\end{array}$ & $90 \pm 11$ & $96 \pm 12$ & $94 \pm 11$ & $96 \pm 11$ & 0.063 \\
\hline $\begin{array}{l}\text { Sleep SBP [mmHg] } \\
\text { median [min-max] }\end{array}$ & 117 [89-170] & 125 [92-178] & 125 [94-173] & 124 [104-169] & 0.068 \\
\hline $\begin{array}{l}\text { Sleep DBP }[\mathrm{mmHg}]^{3} \\
\text { median }[\text { min-max] }\end{array}$ & 69 [51-103] & 73 [54-106] & 70 [54-99] & 70 [57-117] & 0.036 \\
\hline $\begin{array}{l}\text { Sleep MBP [mmHg] } \\
\text { median [min-max] }\end{array}$ & 78 [60-117] & 85 [62-120] & 83 [65-113] & 81 [69-130] & 0.032 \\
\hline $\begin{array}{l}\text { Night decrease ratio (\%) } \\
\text { mean } \pm \text { SD }\end{array}$ & 12 [from -13 to -26 ] & 11 [from -8 to -31$]$ & 10 [from -3 to -35 ] & 13 [from -9 to -33 ] & 0.874 \\
\hline \multicolumn{6}{|c|}{$\begin{array}{l}{ }^{1} \text { value } \leq 0.05 \text { between winter-spring, } p=0.027 \\
{ }^{2} \text { value } \leq 0.05 \text { between winter-spring, } p=0.039 \\
{ }^{3} \text { value } \leq 0.05 \text { between winter-spring, } p=0.021 \\
{ }^{4} \text { value } \leq 0.05 \text { between winter-spring, } p=0.020\end{array}$} \\
\hline
\end{tabular}

$\mathrm{DBP}$ - diastolic blood pressure; MBP — mean blood pressure; SBP — systolic blood pressure 


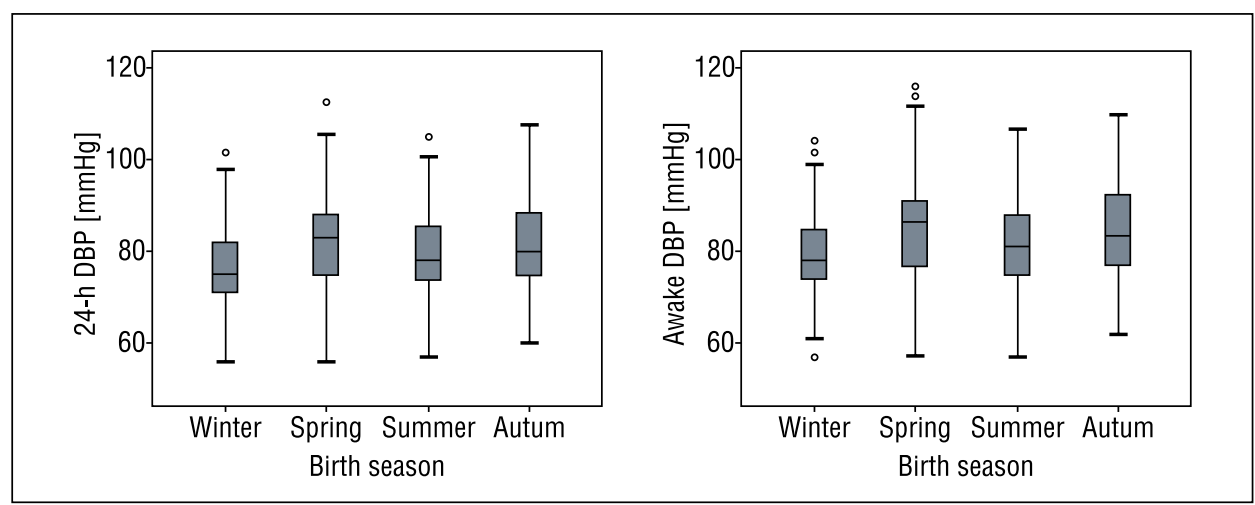

Figure 1. Box plot presentation of the relationship between birth season and 24-h diastolic blood pressure and awake diastolic blood pressure in hypertensive patients. DBP — diastolic blood pressure

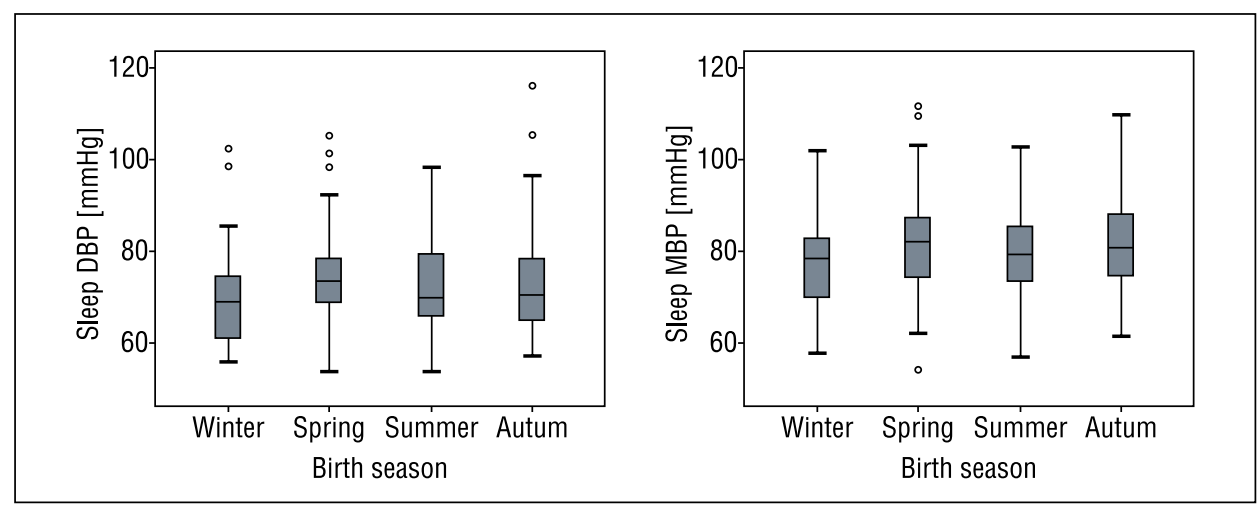

Figure 2. Box plot presentation of the relationship between birth season and sleep diastolic blood pressure and sleep mean blood pressure in hypertensive patients. DBP — diastolic blood pressure; MBP — mean blood pressure

Table IV. Comparison of birth season between dipper and non-dipper hypertensive groups

\begin{tabular}{|l|c|c|c|}
\hline Birth season & $\begin{array}{c}\text { Dipper hypertensive group } \\
(\mathbf{n}=93)\end{array}$ & $\begin{array}{c}\text { Non-dipper hypertensive group } \\
(\mathbf{n}=101)\end{array}$ & p \\
\hline Winter, $\mathrm{n}(\%)$ & $28(30.1)$ & $25(24.8)$ & 0.517 \\
\hline Spring, $\mathrm{n}(\%)$ & $29(31.1)$ & $33(32.7)$ & \\
\hline Summer, $\mathrm{n}(\%)$ & $15(16.1)$ & $24(23.8)$ & \\
\hline Autumn, $\mathrm{n}(\%)$ & $21(22.5)$ & $19(18.8)$ & \\
\hline
\end{tabular}

at the end systole was thinner in pigs born in spring than in those born in other seasons [5]. Another clinical study revealed that adult men born in spring had lower blood pressure than those born in other seasons [2]. Boland et al. found that individuals born in autumn (September-December) had lower risk of cardiovascular events than those born in winter (January-March), and spring (April-June) [1]. Another study revealed that people born in autumn lived longer than those born in spring [6].

Though the underlying mechanisms are unclear, there are many hypotheses about the effect of the season of birth on BP. Several previous studies reported a significant relationship between ultraviolet light, plasma 25(OH)D level and blood pressure [7, 8]. Plasma 25(OH)D displays seasonal variations with a peak in late summer (August-October) and lowest level in early spring (February-April) [9]. However, the effect of vitamin D on BP during life is controversial. Vitamin D and its metabolite $25(\mathrm{OH}) \mathrm{D}$ are believed to cross the placenta as early as four weeks after gestation via megalin, cubilin and vitamin D receptor (VDR) mediated processes [10]. Low maternal vitamin $\mathrm{D}$ levels in prenatal or early 
neonatal life may have effects in later life through the epigenetic process of genomic imprinting [11, 12]. Previous studies have reported that the early postneonatal stage (1-3 months after birth) could be a critical period $[13,14]$. Exposure to sunlight, maternal $25(\mathrm{OH}) \mathrm{D}$ status and plasma $25(\mathrm{OH}) \mathrm{D}$ level may affect blood pressure variations in the early postnatal period. According to these findings, we can say that maternal vitamin D status may affect the child in two periods, prenatal and early postnatal. Those born during summer must have been conceived during winter. People conceived during winter would have lower plasma levels of $25(\mathrm{OH}) \mathrm{D}$ in the embryonic or fetal state and had higher plasma levels of $25(\mathrm{OH}) \mathrm{D}$ in early the postnatal state [15]. The most important period changes depend on explanation hypothesis. Besides, vitamin D concentration may be affected by some other conditions such as pregnancy, estrogen status, obesity, renal and liver disease, vitamin D supplement usage, primary hyperparathyroidism, inflammation, vitamin D binding protein level and some therapeutic procedures such as plasma exchange and peritoneal dialysis [16]. Furthermore, the activities of some hormones (cortisol, melatonin, nitric oxide) are related to ambient light or season [4]. Levels of these hormones may affect life-long blood pressure. We do not know which hypothesis is most correct in explaining the relationship between blood pressure and birth season.

According to our literature review, there have not been any studies about the relationship between the diurnal variation of BP and birth season in hypertensive patients. In our study, we did not find any relationship between non-dipper status and birth season in hypertensive patients. Moreover, there was no association between night decrease ratio and birth season in hypertensive patients. However, there was a very significant relationship between birth season and blood pressure in hypertensive patients independent of non-dipper status. This difference was statistically significant and associated with the winter season. Hypertensive patients born in winter had lower blood pressure. This finding may add to the discussion of some hypotheses based on the previous studies concerning birth season and cardiovascular disorders. In another study, it was demonstrated that birth in winter is related to high dopamine and serotonin activity in the brain [17]. It may affect autonomic activity and diurnal BP. Molfino et al. showed that a low room temperature was a contributing factor toward enhanced sympathetic modulation [18]. Low temperature during the postnatal period is a stress on the newborn and parasympathetic activity may be increased to balance the stress. This ability may be preserved into later life [19].

However, some limitations of this study should be noted. The cross-sectional study design is the main concern. The sample size of our study is relatively low. The findings need to be confirmed in a larger population. The present study was a single center study. We enrolled the study patients in the same geographic area. It may prevent the results of the study from being generalized to other geographic areas. The usage of antihypertensive medication was different among groups. This difference may affect the non-dipper status. Furthermore, the timing of taking these drugs was not recorded in the study. It may change the blood pressure status.

\section{Conclusion}

Birth season was related to diurnal variation in blood pressure in hypertensive patients. Hypertensive individuals born in winter had lower blood pressure, which may be related to cardiovascular events. Thus, we can say that birth season may provide valuable information to evaluate the blood pressure variation of the patients. If our findings are supported by future well-designed studies, we will have valuable data to explain blood pressure variation in hypertensive patients.

\section{Sources of funding}

There are no funders to report for this submission.

\section{Conflict of interest}

None.

\section{References}

1. Boland MR, Shahn Z, Madigan D, et al. Birth month affects lifetime disease risk: a phenome-wide method. J Am Med Inform Assoc. 2015; 22(5): 1042-1053, doi: 10.1093/jamia/ocv046, indexed in Pubmed: 26041386.

2. Banegas JR, Rodríguez-Artalejo F, de la Cruz JJ, et al. Adult men born in spring have lower blood pressure. J Hypertens. 2000; 18(12): 1763-1766, indexed in Pubmed: 11132599.

3. White WB. Ambulatory blood-pressure monitoring in clinical practice. N Engl J Med. 2003; 348(24): 2377-2378, doi: 10.1056/ NEJMp030057, indexed in Pubmed: 12802022.

4. Wehr TA. Effect of seasonal changes in daylength on human neuroendocrine function. Horm Res. 1998; 49(3-4): 118-124, doi: 10.1159/000023157, indexed in Pubmed: 9550111.

5. Huang SY, Lin JH, Lin EC, et al. Effects of birth season, breed, sex, and sire family on cardiac morphology determined in pigs (Sus scrofa domestica) by use of echocardiography. Comp Med. 2001; 51(6): 545-549, indexed in Pubmed: 11924818.

6. Doblhammer G, Vaupel JW. Lifespan depends on month of birth. Proc Natl Acad Sci U S A. 2001; 98(5): 2934-2939, doi: 10.1073/ pnas.041431898, indexed in Pubmed: 11226344. 
7. Rostand SG. Ultraviolet light may contribute to geographic and racial blood pressure differences. Hypertension. 1997; 30 (2 Pt 1): 150-156, indexed in Pubmed: 9260973.

8. Krause R, Bühring M, Hopfenmüller W, et al. Ultraviolet B and blood pressure. Lancet. 1998; 352(9129): 709-710, doi: 10.1016/ S0140-6736(05)60827-6, indexed in Pubmed: 9728997.

9. Rejnmark L, Vestergaard P, Heickendorff L, et al. Determinants of plasma PTH and their implication for defining a reference interval. Clin Endocrinol (Oxf). 2011; 74(1): 37-43, doi: 10.1111/j. 1365-2265.2010.03894.x, indexed in Pubmed: 21039730.

10. Kaludjerovic J, Vieth R. Relationship between vitamin D during perinatal development and health. J Midwifery Womens Health. 2010; 55(6):550560, doi: 10.1016/j.jmwh.2010.02.016, indexed in Pubmed: 20974417.

11. McGrath J. Does 'imprinting' with low prenatal vitamin $D$ contribute to the risk of various adult disorders? Med Hypotheses. 2001; 56(3): 367371, doi: 10.1054/mehy.2000.1226, indexed in Pubmed: 11359362.

12. Við Streym S, Rejnmark L, Mosekilde L, et al. No effect of season of birth on risk of type 1 diabetes, cancer, schizophrenia and ischemic heart disease, while some variations may be seen for pneumonia and multiple sclerosis. Dermatoendocrinol. 2013; 5(2): 309-316, doi: 10.4161/derm.22779, indexed in Pubmed: 24194971.

13. Rivkees SA. Developing circadian rhythmicity. Basic and clinical aspects. Pediatr Clin North Am. 1997; 44(2): 467-487, indexed in Pubmed: 9130930
14. Fernandez JR, Cornelissen G, Tarquini B, et al. Human neonatal infradian, notably circannual, blood pressure and heart rate rhythms, gender and cardiovascular disease risk. Progress in Clinical and Biological Research. 1990(341): 653-664.

15. Brot C, Vestergaard P, Kolthoff N, et al. Vitamin D status and its adequacy in healthy Danish perimenopausal women: relationships to dietary intake, sun exposure and serum parathyroid hormone. Br J Nutr. 2001; 86 Suppl 1: S97-103, indexed in Pubmed: 11520426.

16. Yousefzadeh P, Shapses SA, Wang X. Vitamin D Binding Protein Impact on 25-Hydroxyvitamin D Levels under Different Physiologic and Pathologic Conditions. Int J Endocrinol. 2014; 2014: 981581, doi: 10.1155/2014/981581, indexed in Pubmed: 24868205.

17. Losonczy MF, Mohs RC, Davis KL. Seasonal variations of human lumbar CSF neurotransmitter metabolite concentrations. Psychiatry Res. 1984; 12(1): 79-87, indexed in Pubmed: 6205414.

18. Molfino A, Fiorentini A, Tubani L, et al. Body mass index is related to autonomic nervous system activity as measured by heart rate variability. Eur J Clin Nutr. 2009; 63(10): 1263-1265, doi: 10.1038/ ejcn.2009.35, indexed in Pubmed: 19471292.

19. Huang WL, Hwang BT, Lai CT, et al. Is heart rate variability related to season of birth? Clin Cardiol. 2015; 38(7): 407-412, doi: 10.1002/ clc.22410, indexed in Pubmed: 26212374 